\title{
An Analytical Expression for Magnet Shape Optimization in Surface-Mounted Permanent Magnet Machines
}

\author{
Ali Jabbari $($ ) \\ Department of Mechanical Engineering, Faculty of Engineering, Arak University, Arak 38156-8-8849, Iran; \\ a-jabbari@araku.ac.ir
}

Received: 16 July 2018; Accepted: 2 October 2018; Published: 5 October 2018

\begin{abstract}
Surface-mounted permanent magnet machines are widely used in low and medium speed applications. Pulsating torque components is the most crucial challenge, especially in low-speed applications. Magnet pole shape optimization can be used to mitigate these components. In this research, an analytical model is proposed to calculate the magnetic vector potential in surface-mounted permanent magnet machines. A mathematical expression is also derived for optimal the magnet shape to reduce the cogging torque and electromagnetic torque components. The presented model is based on the resolution of the Laplace's and Poisson's equations in polar coordinates by using the subdomain method and applying hyperbolic functions. The proposed method is applied to the performance computation of a surface-mounted permanent magnet machine, i.e., a 3-phase 12S-10P motor. The analytical results are validated through the finite element analysis (FEA) method.
\end{abstract}

Keywords: surface-mounted PM machines; torque pulsation; magnet shape optimization; analytical expression

\section{Introduction}

Surface-mounted permanent magnet machines are interested in high-performance applications because of their high efficiency and power density. However, the noise and vibration caused by pulsating torque components seriously affect the machine performance. Pulsating torque is greatly affected by the distribution of the magnetic field and the configuration of the permanent magnets. Therefore, pulsating torque mitigation can be performed using magnet shape optimization to obtain a better magnetic field waveform and also to reduce the cogging torque and electromagnetic torque, effectively.

An extensive variety of techniques such as magnet skewing [1-4], magnet-arc optimization [5-9], magnet shape optimization [10], and magnet displacing [2-4,7-9] for minimizing cogging torque in permanent magnet motors is documented in the literature.

A variety of techniques including analytical and numerical methods have been conducted to evaluate the pulsating torque components in electrical machines. Numerical methods like the finite element method (FEA) give accurate results and are time-consuming especially in the first step of the design stage. Semi-analytical methods including conformal mapping [11-14] and Magnetic Equivalent Circuit (MEC) [15-17], and analytical methods including the subdomain model [18-33] are reported to model electrical machines and are useful in the design optimization stage. The subdomain model is more accurate than the other analytical models [15].

Indeed, the global or local saturation effect influences the electromagnetic performances, e.g., on the ripple/cogging torque [34]. To overcome that issue, recently, a new technique to account for 
finite soft-magnetic material permeabilities in the subdomain technique was developed by applying the superposition principle in both directions in polar or Cartesian coordinates [35,36]. According to Reference [37], the Dubas' superposition technique [35,36] is very interesting since it enables the magnetic field calculation in the material of slotted geometries. This technique has been implemented in radial-flux electrical machines considering finite soft-magnetic material permeability [34]. The Dubas's superposition technique could have been used to develop a new model with the consideration of the saturation effect. In References [38-41], an analytical model has been introduced to compute electric machine performance by using the subdomain method.

However, no analytical expression was found at present to calculate the optimal magnet pole shape in surface-mounted permanent magnet machines in order to minimize the pulsating torque components.

The focus of this paper is to derive an analytical expression for the optimal magnet pole shape in surface-mounted permanent magnet machines to reduce pulsating torque components. An analytical model is presented based on the resolution of the Laplace's and Poisson's equations in surface-mounted permanent magnet machines by using the subdomain method whilst considering pole shape optimization. It is shown that the developed model can effectively estimate the magnetic field, cogging torque, electromagnetic torque, back electromotive force and self/mutual inductance. This model is applied to the performance calculation of a surface-mounted permanent magnet motor, i.e., a 3-phase 12S-10P motor. It is shown that the results of the analytical model are in close agreement with the results of the FEA method.

\section{Subdomain Definition}

The schematic representation of the investigated machines is shown in Figure 1. The machine model is divided into four subdomains. The stator which has two subdomains including the $Q_{1}$ slot regions (domain $j$ ), the $Q_{1}$ slot opening regions (domain $i$ ) and the airgap subdomain (region $I I$ ) are shown in Figure 2. The rotor has one subdomain including the permanent magnet regions (domain I), as shown in Figure 3.

The angular position of the $j$-th stator slot and $i$-th stator slot opening are defined as (1) and (2), respectively.

$$
\begin{array}{ccc}
\theta_{j}=-\frac{\beta}{2}+\frac{2 j \pi}{Q_{1}} & \text { with } & 1 \leq j \leq Q_{1} \\
\theta_{i}=-\frac{\alpha}{2}+\frac{2 i \pi}{Q_{1}} & \text { with } & 1 \leq i \leq Q_{1}
\end{array}
$$

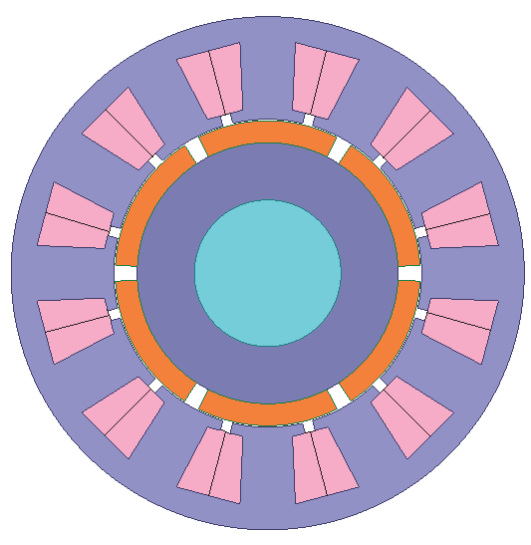

(a)

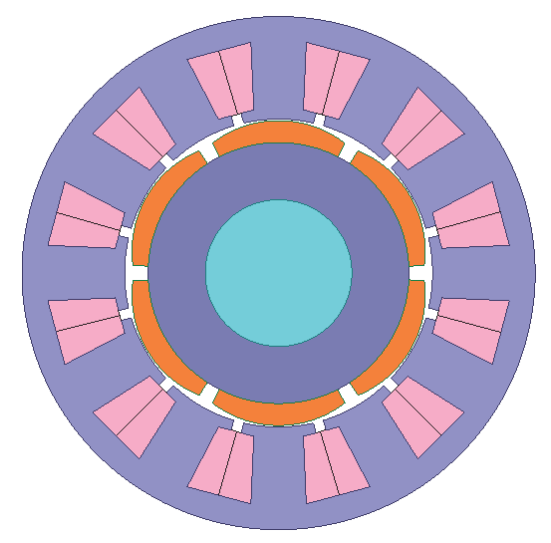

(b)

Figure 1. The geometrical representation of the investigated machines with (a) uniform rotor shape, (b) non-uniform rotor shape. 


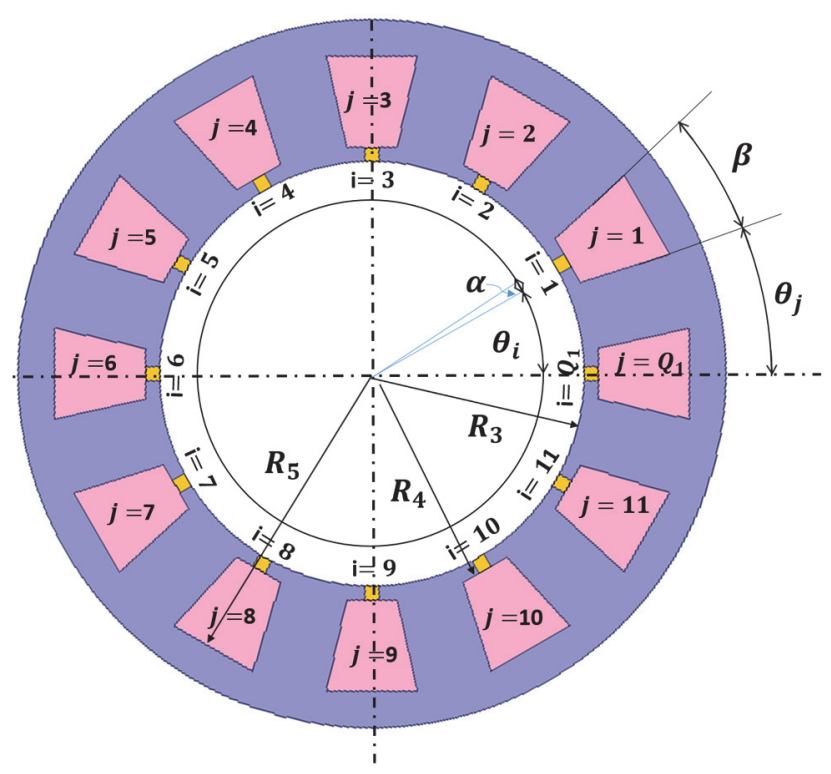

Figure 2. The stator subdomains including the $j$ and $i$ regions.

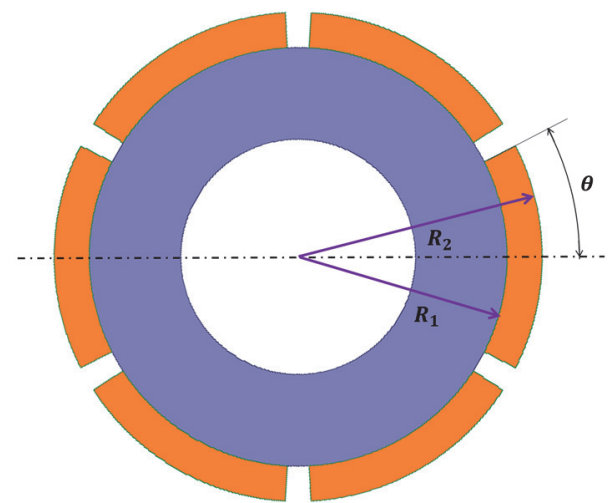

(a)

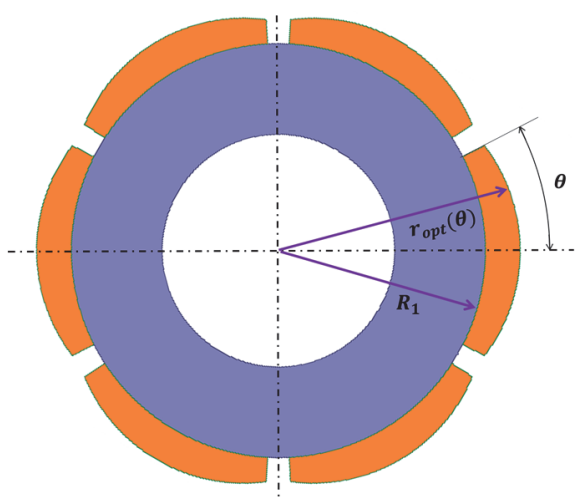

(b)

Figure 3. The rotor permanent magnet subdomain. (a) Uniform rotor, (b) non-uniform rotor.

\section{Magnetic Vector Potential Computation}

The general solution to Laplace's or Poisson's equations in each subdomain is developed in this section. The Laplace equation can be described in the polar form as

$$
\frac{\partial^{2} A_{z}}{\partial r^{2}}+\frac{1}{r} \frac{\partial A_{z}}{\partial r}+\frac{1}{r^{2}} \frac{\partial^{2} A_{z}}{\partial \theta^{2}}=0 \quad \text { for }\left\{\begin{array}{c}
R_{1} \leq r \leq R_{2} \\
\theta_{1} \leq \theta \leq \theta_{2}
\end{array}\right.
$$

By replacing $r$ by $R_{1} e^{-t}$, one obtains

$$
\frac{\partial^{2} A_{z}}{\partial t^{2}}+\frac{\partial^{2} A_{z}}{\partial \theta^{2}}=0 \quad \text { for } \quad\left\{\begin{array}{c}
\ln \left(\frac{R_{1}}{R_{2}}\right) \leq t \leq 0 \\
\theta_{1} \leq \theta \leq \theta_{2}
\end{array}\right.
$$

The 2D analytical model in quasi-Cartesian coordinates is formulated with the following assumptions:

- The end effects are neglected (i.e., the machine is infinitely long: the magnetic variables are independent of $\mathrm{z}$ ).

- The stator is assumed to be infinitely permeable (i.e., the saturation effect is neglected) with zero electrical conductivity. 
- The relative magnetic permeability and electrical conductivity of the solid rotor and shaft are assumed to be constant.

- The current density in the slots has only one component along the z-axis.

3.1. Magnetic Vector Potential in the Stator Slot Subdomain (Region j)

The Poisson equation in the stator slot subdomain is given by

$$
\frac{\partial^{2} A_{z j}}{\partial t^{2}}+\frac{\partial^{2} A_{z j}}{\partial \theta^{2}}=-\mu_{0} J_{z j} R_{4}^{2} e^{-2 t} \quad \text { for } \quad\left\{\begin{array}{c}
t_{1} \leq t \leq t_{2} \\
\theta_{j} \leq \theta \leq \theta_{j}+\beta
\end{array}\right.
$$

where $t_{1}=\ln \left(\frac{R_{4}}{R_{5}}\right), t_{2}=0$ and $J_{z j}$ is the slot current density.

The Neumann boundary conditions at the bottom and at each side of the slot are obtained as

$$
\begin{gathered}
\left.\frac{\partial A_{z j}}{\partial \theta}\right|_{\theta=\theta_{j}}=0 \text { and }\left.\frac{\partial A_{z j}}{\partial \theta}\right|_{\theta=\theta_{j}+\beta}=0 \\
\left.\frac{\partial A_{z j}}{\partial t}\right|_{t=t_{1}}=0
\end{gathered}
$$

The general solution of Equation (5) using the separation of variables method is given by

$$
\begin{aligned}
A_{z j}(t, \theta)=a_{0}{ }^{j}- & \frac{1}{2} \mu_{0} J_{z j} R_{5}^{2}\left(e^{-2 t_{1}} t+\frac{1}{2} e^{-2 t+2 t_{1}}\right) \\
& +\sum_{h=1}^{\infty}\left(a_{h}{ }^{j} \frac{\beta}{h \pi} \frac{\operatorname{Cosh}\left(\frac{h \pi}{\beta}\left(t-t_{1}\right)\right)}{\operatorname{Sinh}\left(\frac{h \pi}{\beta}\left(t_{2}-t_{1}\right)\right)}\right) \operatorname{Cos}\left(\frac{h \pi}{\beta}\left(\theta-\theta_{j}\right)\right)
\end{aligned}
$$

where $h$ is a positive integer and the coefficients $a_{0}{ }^{j}$ and $a_{h}{ }^{j}$ are determined based on the continuity and interface conditions.

The continuity of the magnetic vector potential between the subdomain $j$ and the region $i$ leads to

$$
\left.\frac{\partial A_{z j}}{\partial t}\right|_{t=t_{2}}=f(\theta)=\left\{\begin{array}{cc}
\left.\frac{\partial A_{z i}}{\partial t}\right|_{t=t_{3}} \text { for } & \theta_{i} \leq \theta \leq \theta_{i}+\alpha \\
0 & \text { elsewhere }
\end{array}\right.
$$

The interface condition (9) gives

$$
\begin{gathered}
\mu_{0} J_{z j} \sinh \left(t_{1}\right)=\frac{1}{\beta} \int_{\theta_{j}}^{\theta_{j}+\beta} f(\theta) d \theta \\
a_{h}{ }^{j}=\frac{2}{\beta} \int_{\theta_{j}}^{\theta_{j}+\beta} f(\theta) \operatorname{Cos}\left(\frac{h \pi}{\beta}\left(\theta-\theta_{j}\right)\right) d \theta
\end{gathered}
$$

\subsection{Magnetic Vector Potential in the Stator Slot Opening Subdomain (Region i)}

The Laplace equation in the stator second inner slot opening subdomain is given by

$$
\frac{\partial^{2} A_{z i}}{\partial t^{2}}+\frac{\partial^{2} A_{z i}}{\partial \theta^{2}}=0 \quad \text { for } \quad\left\{\begin{array}{c}
t_{3} \leq t \leq t_{4} \\
\theta_{i} \leq \theta \leq \theta_{i}+\alpha
\end{array}\right.
$$

where $t_{3}=\ln \left(\frac{R_{3}}{R_{4}}\right)$ and $t_{4}=0$. 
The Neumann boundary conditions at the bottom and at each side of the slot are obtained as

$$
\left.\frac{\partial A_{z i}}{\partial \theta}\right|_{\theta=\theta_{i}}=0 \text { and }\left.\frac{\partial A_{z i}}{\partial \theta}\right|_{\theta=\theta_{i}+\alpha}=0
$$

The general solution of Equation (12) using the separation of variables method is given by

$$
\begin{aligned}
& A_{z i}(t, \theta)=a_{0}{ }^{i}+b_{0}{ }^{i} t \\
& +\sum_{k=1}^{\infty}\left(\frac{\operatorname{Sinh}\left(\frac{k \pi}{\alpha}\left(t-t_{4}\right)\right)}{\operatorname{Sinh}\left(\frac{k \pi}{\alpha}\left(t_{3}-t_{4}\right)\right)} a_{k}{ }^{i}+\frac{\operatorname{Sinh}\left(\frac{k \pi}{\alpha}\left(t-t_{3}\right)\right)}{\operatorname{Sinh}\left(\frac{k \pi}{\alpha}\left(t_{4}-t_{3}\right)\right)} b_{k}{ }^{i}\right) \operatorname{Cos}\left(\frac{k \pi}{\alpha}\left(\theta-\theta_{i}\right)\right)
\end{aligned}
$$

where $k$ is a positive integer and the coefficients, $a_{0}{ }^{i}, b_{0}{ }^{i}, a_{k}{ }^{i}$ and $b_{k}{ }^{i}$ are determined based on the continuity and interface conditions.

The continuity of the magnetic vector potential between the subdomain $l$ and the regions $i$ and $I I$ leads to

$$
\begin{array}{ccc}
A z i\left(t_{4}, \theta\right)=A z I I\left(t_{5}, \theta\right) & \text { for } & \theta_{i} \leq \theta \leq \theta_{i}+\alpha \\
A z i\left(t_{3}, \theta\right)=A z j\left(t_{4}, \theta\right) & \text { for } & \theta_{i} \leq \theta \leq \theta_{i}+\alpha
\end{array}
$$

The interface condition (15) gives

$$
\begin{gathered}
a_{0}{ }^{i}=\frac{1}{\alpha} \int_{\theta_{l}}^{\theta_{i}+\alpha} \operatorname{AII}\left(t_{5}, \theta\right) d \theta \\
b_{k}{ }^{i}=\frac{2}{\alpha} \int_{\theta_{i}}^{\theta_{i}+\alpha} \operatorname{AII}\left(t_{5}, \theta\right) \operatorname{Cos}\left(\frac{h \pi}{\alpha}\left(\theta-\theta_{i}\right)\right) d \theta
\end{gathered}
$$

The interface condition (16) gives

$$
\begin{gathered}
a_{0}{ }^{i}+\ln \left(\frac{R_{3}}{R_{4}}\right) b_{0}{ }^{i}=\frac{1}{\alpha} \int_{\theta_{i}}^{\theta_{i}+\alpha} A z j\left(t_{4}, \theta\right) d \theta \\
a_{k}^{i}=\frac{2}{\alpha} \int_{\theta_{i}}^{\theta_{i}+\alpha} A z j\left(t_{4}, \theta\right) \operatorname{Cos}\left(\frac{k \pi}{\alpha}\left(\theta-\theta_{i}\right)\right) d \theta
\end{gathered}
$$

\subsection{Magnetic Vector Potential in the Air-Gap Subdomain (Region II)}

The Laplace equation in the air-gap subdomain is given by

$$
\frac{\partial^{2} A_{z I I}}{\partial t^{2}}+\frac{\partial^{2} A_{z I I}}{\partial \theta^{2}}=0 \quad \text { for } \quad\left\{\begin{array}{c}
t_{5} \leq t \leq t_{6} \\
0 \leq \theta \leq 2 \pi
\end{array}\right.
$$

where $t_{5}=\ln \left(\frac{R_{2}}{R_{3}}\right)$ and $t_{6}=0$.

The general solution of Equation (21), considering the periodicity boundary conditions is obtained as

$$
\begin{aligned}
& A_{z I I}(\mathrm{t}, \theta)=\sum_{n=1}^{\infty}\left(\frac{1}{n} \frac{\operatorname{Cosh}\left(n\left(\mathrm{t}-\mathrm{t}_{6}\right)\right)}{\operatorname{Sinh}\left(n\left(\mathrm{t}_{5}-\mathrm{t}_{6}\right)\right)} a_{n}{ }^{I I}+\frac{1}{n} \frac{\operatorname{Cosh}\left(n\left(\mathrm{t}-\mathrm{t}_{5}\right)\right)}{\operatorname{Sinh}\left(n\left(\mathrm{t}_{6}-\mathrm{t}_{5}\right)\right)} b_{n}{ }^{I I}\right) \operatorname{Cos}(n \theta) \\
& +\sum_{n=1}^{\infty}\left(\frac{1}{n} \frac{\cosh \left(n\left(\mathrm{t}-\mathrm{t}_{6}\right)\right)}{\operatorname{Sinh}\left(n\left(\mathrm{t}_{5}-\mathrm{t}_{6}\right)\right)} c_{n}{ }^{I I}+\frac{1}{n} \frac{\operatorname{Cosh}\left(n\left(\mathrm{t}-\mathrm{t}_{5}\right)\right)}{\operatorname{Sinh}\left(n\left(\mathrm{t}_{6}-\mathrm{t}_{5}\right)\right)} d_{n}{ }^{I I}\right) \operatorname{Sin}(n \theta)
\end{aligned}
$$

where $n$ is a positive integer.

The coefficients $a_{n}{ }^{I I}, b_{n}{ }^{I I}, c_{n}{ }^{I I}$ and $d_{n}{ }^{I I}$ are determined by considering the continuity of the magnetic vector potential between the internal airgap subdomain $I I$ and the region $i$ using a Fourier series expansion of interface condition (23) and (24) over the airgap interval. 
The continuity of the magnetic vector potential between the internal airgap subdomain II and the regions $i$ and leads to

$$
\begin{gathered}
\left.\frac{\partial A_{z I I}}{\partial t}\right|_{t=\mathrm{t}_{5}}=g(\theta)=\left\{\begin{array}{cc}
\left.\frac{\partial A_{z i}}{\partial t}\right|_{t=t_{4}} \text { for } & \theta_{i} \leq \theta \leq \theta_{i}+\alpha \\
0 & \text { elsewhere }
\end{array}\right. \\
\left.\frac{\partial A_{z I I}}{\partial t}\right|_{t=\mathrm{t}_{6}}=h(\theta)=\left\{\begin{array}{cc}
\left.\frac{\partial A_{z I}}{\partial t}\right|_{t=t_{7}} \text { for } & \theta_{k} \leq \theta \leq \theta_{k}+\gamma \\
0 & \text { elsewhere }
\end{array}\right.
\end{gathered}
$$

The interface condition (23) gives

$$
\begin{aligned}
& {a_{n}{ }^{I I}}^{I}=\frac{2}{2 \pi} \int_{\theta_{i}}^{\theta_{i}+\alpha} g(\theta) \cos (n \theta) d \theta \\
& {c_{n}{ }^{I I}}=\frac{2}{2 \pi} \int_{\theta_{i}}^{\theta_{i}+\alpha} g(\theta) \operatorname{Sin}(n \theta) d \theta
\end{aligned}
$$

The interface condition (24) gives

$$
\begin{aligned}
& b_{n}{ }^{I I}=\frac{2}{2 \pi} \int_{\theta_{k}}^{\theta_{k}+\gamma} h(\theta) \operatorname{Cos}(n \theta) d \theta \\
& d_{n}{ }^{I I}=\frac{2}{2 \pi} \int_{\theta_{k}}^{\theta_{k}+\gamma} h(\theta) \sin (n \theta) d \theta
\end{aligned}
$$

3.4. Magnetic Vector Potential in the Rotor Permanent Magnet Subdomain (Region I)

The Poisson equation in the rotor permanent magnet subdomain is given by

$$
\frac{\partial^{2} A_{z I}}{\partial t^{2}}+\frac{\partial^{2} A_{z I}}{\partial \theta^{2}}=-\mu_{0} R_{1} e^{-t}\left(M_{\theta}-\frac{\partial M_{r}}{\partial \theta}\right) \quad \text { for } \quad\left\{\begin{array}{c}
t_{7} \leq t \leq t_{8} \\
0 \leq \theta \leq 2 \pi
\end{array}\right.
$$

where $t_{7}=\ln \left(\frac{R_{1}}{R_{2}}\right)$ and $t_{8}=0, M_{\theta}$ and $M_{r}$ are the tangential and radial components of magnetization.

\subsubsection{Radial Magnetization}

The radial and tangential components of radial magnetization for the surface-mounted design can be expressed as

$$
\begin{gathered}
M_{r n}=\frac{4 B_{r}}{\mu_{0} n \pi} \operatorname{Sin}\left(\frac{n \pi \alpha_{p}}{2}\right) \\
M_{\theta n}=0
\end{gathered}
$$

where $\alpha_{p}$ is the magnet pole width to magnet pitch ratio.

\subsubsection{Parallel Magnetization}

The radial and tangential components of the parallel magnetization for the surface-mounted design can be expressed as

$$
\begin{aligned}
& M_{r n}=\frac{B_{r}}{\mu_{0}} \alpha_{p}\left[A_{1 n}\left(\alpha_{p}\right)+A_{2 n}\left(\alpha_{p}\right)\right] \\
& M_{\theta n}=\frac{B_{r}}{\mu_{0}} \alpha_{p}\left[A_{1 n}\left(\alpha_{p}\right)-A_{2 n}\left(\alpha_{p}\right)\right]
\end{aligned}
$$


where

$$
\begin{array}{r}
A_{1 n}\left(\alpha_{p}\right)=\frac{\operatorname{Sin}\left((n p+1) \frac{\pi \alpha_{p}}{2 p}\right)}{(n p+1) \frac{\pi \alpha_{p}}{2 p}} \\
A_{2 n}\left(\alpha_{p}\right)=\left\{\begin{array}{cc}
\frac{\operatorname{Sin}\left((n p-1) \frac{\pi \alpha_{p}}{2 p}\right)}{(n p-1) \frac{\pi \alpha_{p}}{2 p}} & \text { for } n p \neq 1 \\
1 & \text { for } n p=1
\end{array}\right.
\end{array}
$$

For a surface-mounted design, the Neumann boundary conditions at the bottom of the permanent magnet are obtained as

$$
\left.\frac{\partial A_{z I}}{\partial t}\right|_{t=t_{8}}=0
$$

The general solution of Equation (29) using the separation of variables method is given by

$$
\begin{gathered}
A_{z I}(t, \theta)=\sum_{n=1}^{\infty}\left(\begin{array}{c}
a_{n}^{I} \frac{\cosh \left(n\left(t-t_{8}\right)\right)}{\cosh \left(n\left(t_{7}-t_{8}\right)\right)} \\
+X_{n}(t) \operatorname{Cos}\left(\frac{n \pi \alpha_{p}}{2 \alpha_{r}}\right)
\end{array}\right) \cos (n \theta) \\
+\sum_{n=1}^{\infty}\left(\begin{array}{c}
c_{n}^{I} \frac{\cosh \left(n\left(t-t_{8}\right)\right)}{\cosh \left(n\left(t_{7}-t_{8}\right)\right)} \\
+X_{n}(t) \cdot \operatorname{Sin}\left(\frac{n \pi \alpha_{p}}{2 \alpha_{r}}\right)
\end{array}\right) \sin (n \theta) \\
X_{n}(t)=\left(1+\frac{1}{n} e^{(n+1) t}\right) f_{n}(t)-\frac{\cosh \left(n\left(t-t_{8}\right)\right)}{\operatorname{Cosh}\left(n\left(t_{7}-t_{8}\right)\right)}\left(1+\frac{1}{n} e^{(n+1) t_{7}}\right) f_{n}\left(t_{7}\right) \\
f_{n}(t)=\left\{\begin{array}{cc}
\mu_{0} \frac{n p M_{r n}+M_{\theta n}}{1-n p^{2}} R_{1} e^{-t} & \text { if } n p \neq 1 \\
-\mu_{0} \frac{M_{r n}+M_{\theta n}}{2} R_{1} e^{-t} \ln \left(R_{1} e^{-t}\right) & \text { if } n p=1
\end{array}\right.
\end{gathered}
$$

where $n$ is a positive integer and the coefficients $a_{n}{ }^{I}$ and $c_{n}{ }^{I}$ are determined based on the continuity and interface conditions.

The continuity of the magnetic vector potential between the subdomain $I$ and the regions $I I$ leads to

$$
A_{z I}\left(t_{7}, \theta\right)=A_{z I I}\left(t_{6}, \theta\right)
$$

The interface condition (40) gives

$$
\begin{aligned}
& a_{n}^{I}=\frac{2}{2 \pi} \int_{0}^{2 \pi} A_{z I I}\left(t_{6}, \theta\right) \cdot \operatorname{Cos}(n \theta) d \theta \\
& c_{n}^{I}=\frac{2}{2 \pi} \int_{0}^{2 \pi} A_{z I I}\left(t_{6}, \theta\right) \cdot \operatorname{Sin}(n \theta) d \theta
\end{aligned}
$$

\section{Magnet Pole Shape Optimization}

The general solution for the magnetic potential distribution in the air-gap subdomain is

$$
A_{z I I}(\mathrm{t} . \theta)=\sum_{n=1}^{\infty}\left(\frac{1}{n} \frac{\operatorname{Cosh}\left(n\left(\mathrm{t}-\mathrm{t}_{6}\right)\right)}{\operatorname{Sinh}\left(n\left(\mathrm{t}_{5}-\mathrm{t}_{6}\right)\right)} a_{n}{ }^{I I}+\frac{1}{n} \frac{\operatorname{Cosh}\left(n\left(\mathrm{t}-\mathrm{t}_{5}\right)\right)}{\operatorname{Sinh}\left(n\left(\mathrm{t}_{6}-\mathrm{t}_{5}\right)\right)} b_{n}{ }^{I I}\right) \operatorname{Cos}(n \theta)
$$

The normal flux density $B_{r}$ is defined as

$$
B_{r}=-\mu_{0} \frac{\partial A_{z I I}}{\partial r}=-\mu_{0} \frac{e^{t_{5}}}{R_{2}} \frac{\partial A_{z I I}}{\partial t}
$$

As the permeability of the stator/rotor iron core is much larger than that of air, the following boundary conditions are employed 
- The scalar magnetic potential is expressed as $A_{I I}=0$ in the inner stator surface

$$
A_{z I I}\left(t_{5}, 0\right)=0
$$

or

$$
\sum_{n=1}^{\infty}\left(\frac{1}{n} \frac{\operatorname{Cosh}\left(n\left(\mathfrak{t}_{5}\right)\right)}{\operatorname{Sinh}\left(n\left(\mathfrak{t}_{5}\right)\right)} a_{n}{ }^{I I}-\frac{1}{n} \frac{1}{\operatorname{Sinh}\left(n\left(\mathfrak{t}_{5}\right)\right)} b_{n}{ }^{I I}\right)=0
$$

- The normal flux density waveforms is sinusoidal in the inner stator surface and expressed as $B_{r}=B_{\max } \cos (\theta)$. Therefore,

$$
-\mu_{0} \frac{e^{t_{5}}}{R_{2}} \frac{\partial A_{z I I}\left(t_{5}, \theta\right)}{\partial t}=B_{\max }
$$

or

$$
-\mu_{0} \frac{e^{t_{5}}}{R_{2}}\left(\frac{\operatorname{Sinh}\left(n\left(\mathbf{t}_{5}-t_{6}\right)\right)}{\operatorname{Sinh}\left(n\left(\mathbf{t}_{5}-t_{6}\right)\right)} a_{n}{ }^{I I}+\frac{\operatorname{Sinh}\left(n\left(\mathbf{t}_{5}-\mathbf{t}_{5}\right)\right)}{\operatorname{Sinh}\left(n\left(\mathbf{t}_{6}-t_{5}\right)\right)} b_{n}{ }^{I I}\right)=B_{\max }
$$

From the boundary conditions (46) and (48), we can get

$$
\begin{gathered}
b_{1}{ }^{I I}=\operatorname{Cosh}\left(\left(\mathbf{t}_{5}\right)\right) a_{1}{ }^{I I} \\
\left\{\begin{array}{lr}
a_{1}{ }^{I I}=-\frac{B_{\max } R_{3}}{\mu_{0}} & n=1 \\
b_{1}{ }^{I I}=-\frac{B_{\max } R_{3}}{\mu_{0}} \operatorname{Cosh}\left(\left(\mathbf{t}_{5}\right)\right) & n=1 \\
a_{n}{ }^{I I}=0 & n=3,5,7 \\
b_{n}{ }^{I I}=0 & n=3,5,7
\end{array}\right.
\end{gathered}
$$

At the position of $\theta=0$, the magnetic potential is expressed as

$$
B_{r I I}\left(\mathrm{t}_{6}, 0\right)=-\frac{\mu_{0}}{R_{2}}\left(\frac{\operatorname{Sinh}\left(n\left(\mathrm{t}_{6}-\mathrm{t}_{6}\right)\right)}{\operatorname{Sinh}\left(n\left(\mathrm{t}_{5}-\mathrm{t}_{6}\right)\right)} a_{1}{ }^{I I}-\frac{\operatorname{Sinh}\left(n\left(\mathrm{t}_{6}-\mathrm{t}_{5}\right)\right)}{\operatorname{Sinh}\left(n\left(\mathrm{t}_{5}-\mathrm{t}_{6}\right)\right)} b_{1}{ }^{I I}\right)
$$

or

$$
B_{r I I}\left(\mathrm{t}_{6}, 0\right)=-\frac{\mu_{0}}{R_{2}} b_{1}{ }^{I I}=\frac{\mu_{0}}{R_{2}} \frac{B_{\max } R_{3}}{\mu_{0}} \operatorname{Cosh}\left(\left(\mathrm{t}_{5}\right)\right)
$$

In the outer surface of the rotor, the magnetic potential can be derived as

$$
B_{r I I}\left(\mathrm{t}_{6}, 0\right)=B_{r I I}(t, 0)
$$

or

$$
B_{r I I}^{2}\left(\mathrm{t}_{6}, 0\right)=B_{r I I}^{2}(\mathrm{t}, \theta)
$$

or

$$
\left(\frac{\mu_{0}}{R_{2}} \frac{B_{\max } R_{3}}{\mu_{0}} \operatorname{Cosh}\left(\left(\mathrm{t}_{5}\right)\right)\right)^{2}=\left(-\frac{\mu_{0}}{R_{2}}\left(\begin{array}{c}
\frac{\sinh \left(n\left(\mathrm{t}_{-}-\mathrm{t}_{6}\right)\right)}{\left.\operatorname{Sinh}\left(\mathrm{t}_{5}-\mathrm{t}_{6}\right)\right)} a_{1}{ }^{I I} \\
-\frac{\operatorname{Sinh}\left(n\left(\mathrm{t}--_{5}\right)\right)}{\operatorname{Sinh}\left(n\left(\mathrm{t}_{5}-\mathrm{t}_{6}\right)\right)} b_{1}{ }^{I I}
\end{array}\right) \operatorname{Cos}(\theta)\right)^{2}
$$

or

$$
t_{\text {opt }}(\theta)=\operatorname{Cosh}^{-1}\left\{\frac{\operatorname{Cosh}\left(t_{5}\right)}{\operatorname{Cos}(\theta)}\right\}+t_{5}
$$

Therefore, the optimum magnet radii can be expressed as

$$
r_{o p t}=\frac{R_{1}}{\exp \left(\operatorname{Cosh}^{-1}\left\{\frac{\operatorname{Cosh}\left(t_{5}\right)}{\operatorname{Cos}(\theta)}\right\}+t_{5}\right)}
$$




\section{Performance Calculation}

The electromagnetic torque is obtained using the Maxwell stress tensor and expressed as

$$
T_{e}=\frac{L_{s}}{\mu_{0}} \int_{0}^{2 \pi} B I I_{r}\left(t_{e}, \theta\right) B I I_{\theta}\left(t_{e}, \theta\right) d \theta
$$

where $L_{s}$ is the axial length of the motor and $t_{e}$ is calculated by

$$
\begin{gathered}
t_{e}=\ln \left(\frac{R_{2}}{R_{e}}\right) \\
R_{e}=\left(R_{2}+R_{3}\right) / 2
\end{gathered}
$$

The final expression of the electromagnetic torque can be expressed as

$$
T_{e}=\frac{\pi L_{s}}{\mu_{0}} \sum_{n=1}^{\infty}\left(M_{n} N_{n}+O_{n} P_{n}\right)
$$

where,

$$
\begin{aligned}
& M_{n}=-\frac{1}{R_{e}} \frac{\operatorname{Cosh}\left(n\left(\mathrm{t}_{\mathrm{e}}-\mathrm{t}_{6}\right)\right)}{\operatorname{Sinh}\left(n\left(\mathrm{t}_{5}-\mathrm{t}_{6}\right)\right)} a_{n}{ }^{I I}-\frac{1}{R_{e}} \frac{\operatorname{Cosh}\left(n\left(\mathrm{t}_{\mathrm{e}}-\mathrm{t}_{5}\right)\right)}{\operatorname{Sinh}\left(n\left(\mathrm{t}_{6}-\mathrm{t}_{5}\right)\right)} b_{n}{ }^{I I} \\
& N_{n}=-\frac{1}{R_{e}} \frac{\operatorname{Sinh}\left(n\left(\mathrm{t}_{\mathrm{e}}-\mathrm{t}_{6}\right)\right)}{\operatorname{Sinh}\left(n\left(\mathrm{t}_{5}-\mathrm{t}_{6}\right)\right)} c_{n}{ }^{I I}-\frac{1}{R_{e}} \frac{\operatorname{Sinh}\left(n\left(\mathrm{t}_{\mathrm{e}}-\mathrm{t}_{5}\right)\right)}{\operatorname{Sinh}\left(n\left(\mathrm{t}_{6}-\mathrm{t}_{5}\right)\right)} d_{n}{ }^{I I} \\
& O_{n}=\frac{1}{R_{e}} \frac{\operatorname{Cosh}\left(n\left(\mathrm{t}_{\mathrm{e}}-\mathrm{t}_{6}\right)\right)}{\operatorname{Sinh}\left(n\left(\mathrm{t}_{5}-\mathrm{t}_{6}\right)\right)} c_{n}{ }^{I I}+\frac{1}{R_{e}} \frac{\operatorname{Cosh}\left(n\left(\mathrm{t}_{\mathrm{e}}-\mathrm{t}_{5}\right)\right)}{\operatorname{Sinh}\left(n\left(\mathrm{t}_{6}-\mathrm{t}_{5}\right)\right)} d_{n}{ }^{I I} \\
& P_{n}=-\frac{1}{R_{e}} \frac{\sinh \left(n\left(\mathrm{t}_{\mathrm{e}}-\mathrm{t}_{6}\right)\right)}{\operatorname{Sinh}\left(n\left(\mathrm{t}_{5}-\mathrm{t}_{6}\right)\right)} a_{n}{ }^{I I}-\frac{1}{R_{e}} \frac{\operatorname{Sinh}\left(n\left(\mathrm{t}_{\mathrm{e}}-\mathrm{t}_{5}\right)\right)}{\operatorname{Sinh}\left(n\left(\mathrm{t}_{6}-\mathrm{t}_{5}\right)\right)} b_{n}{ }^{I I}
\end{aligned}
$$

For single layer winding, the phase flux vector is calculated by

$$
\left[\begin{array}{l}
\psi_{a} \\
\psi_{b} \\
\psi_{c}
\end{array}\right]=N_{c} C^{T}\left[\begin{array}{lllll}
\varphi_{1} & \varphi_{2} & \varphi_{3} & \ldots & \varphi_{Q_{2}}
\end{array}\right]
$$

where $N_{c}$ is the number of conductors in the stator slot, $C$ is a matrix connection between the stator slots and phase connections, and $\varphi$ is the slot flux.

For the stator slots, $\varphi$ is given by

$$
\varphi_{i}=-\frac{L_{S} R_{4}^{2}}{k_{f} S} \int_{0}^{\beta} \int_{0}^{t_{8}} A_{m i}(t, \theta) e^{-2 t} d t d \theta
$$

where $k_{f}$ is the stator fill factor and is the area of the stator slot.

For double-layer winding, the phase flux vector is calculated by

$$
\left[\begin{array}{l}
\psi_{a} \\
\psi_{b} \\
\psi_{c}
\end{array}\right]=\left[\begin{array}{l}
\psi 1_{a} \\
\psi 1_{b} \\
\psi 1_{c}
\end{array}\right]+\left[\begin{array}{l}
\psi 2_{a} \\
\psi 2_{b} \\
\psi 2_{c}
\end{array}\right]
$$

where

$$
\left[\begin{array}{l}
\psi 1_{a} \\
\psi 1_{b} \\
\psi 1_{c}
\end{array}\right]=\frac{N_{c}}{2} C_{1}^{T}\left[\begin{array}{lllll}
\varphi_{11} & \varphi_{12} & \varphi_{13} & \ldots & \varphi_{1 Q_{2}}
\end{array}\right]
$$

and

$$
\left[\begin{array}{l}
\psi 2_{a} \\
\psi 2_{b} \\
\psi 2_{c}
\end{array}\right]=\frac{N_{c}}{2} C_{2}^{T}\left[\begin{array}{lllll}
\varphi_{21} & \varphi_{22} & \varphi_{23} & \ldots & \varphi_{2 Q_{2}}
\end{array}\right]
$$


For the stator slots, $\varphi$ is given by

$$
\begin{aligned}
& \varphi_{1 i}=-\frac{2 L_{s} R_{4}^{2}}{k_{f} S} \int_{0}^{\frac{\beta}{2}} \int_{0}^{t_{8}} A_{m i}(t, \theta) e^{-2 t} d t d \theta \\
& \varphi_{2 i}=-\frac{2 L_{s} R_{4}^{2}}{k_{f} S} \int_{\frac{\beta}{2}}^{\beta} \int_{0}^{t_{8}} A_{m i}(t, \theta) e^{-2 t} d t d \theta
\end{aligned}
$$

The back-EMF of phase A is given by

$$
E_{a}=\omega \frac{d \psi_{a}}{d \theta_{r}}
$$

where $\omega$ is the rotor angular speed and $\psi_{a}$ is the flux linkage per phase A.

The stator inductance (self-inductance) of phase $\mathrm{A}$ is given by

$$
L=\frac{\psi_{a}}{I_{A}}
$$

where $I_{A}$ is the peak current in phase A.

The mutual inductance of phase $\mathrm{A}$ and phase $\mathrm{B}$ is given by

$$
M=\frac{N \varphi_{A B}}{I_{B}}
$$

where $N$ is the number of phase turns, $\varphi_{A B}$ is magnetic flux in phase $\mathrm{A}$, and $I_{B}$ is the peak current in phase B.

\section{Model Evaluation}

In this section, the presented analytical model is used to study the magnetic flux density, electromagnetic torque, and back-electromotive force of a 12S-10P motor. The results of the analytical method are then verified by the results of the finite element method. A 2D model of the studied brushless permanent magnet motor is shown in Figure 4 and the motor parameters are given in Table 1. The PM magnetization is radial. The slot contains two coils as shown in Figure 4a. In order to have a good precision in the analytical evaluation, the number of harmonic terms used in the computations is equal to 50 (air-gap and PM subdomains) and 30 (slots and slot-opening subdomain).

We have to solve a system of linear equations with the same number of unknowns (i.e., 12). The matrix connection between the stator slots and phase connections of each layer for the investigated motor are given by

$$
\begin{gathered}
C_{1}=\left[\begin{array}{cccccccccccc}
1 & -1 & 0 & 0 & 0 & 0 & -1 & 1 & 0 & 0 & 0 & 0 \\
0 & 0 & -1 & 1 & 0 & 0 & 0 & 0 & 1 & -1 & 0 & 0 \\
0 & 0 & 0 & 0 & 1 & -1 & 0 & 0 & 0 & 0 & -1 & 1
\end{array}\right] \\
C_{2}=\left[\begin{array}{cccccccccccc}
0 & -1 & 1 & 1 & 0 & 0 & 0 & 1 & -1 & 0 & 0 & 0 \\
0 & 0 & 0 & 1 & -1 & 1 & 0 & 0 & 0 & -1 & 1 & 0 \\
-1 & 1 & 0 & 0 & 1 & 0 & 0 & 1 & 0 & 0 & 0 & 1
\end{array}\right]
\end{gathered}
$$




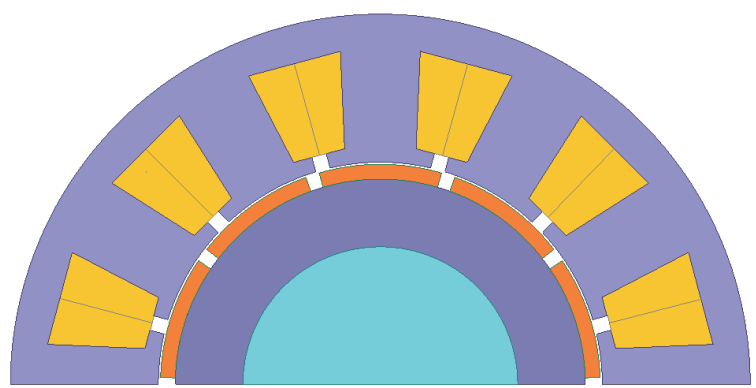

(a)

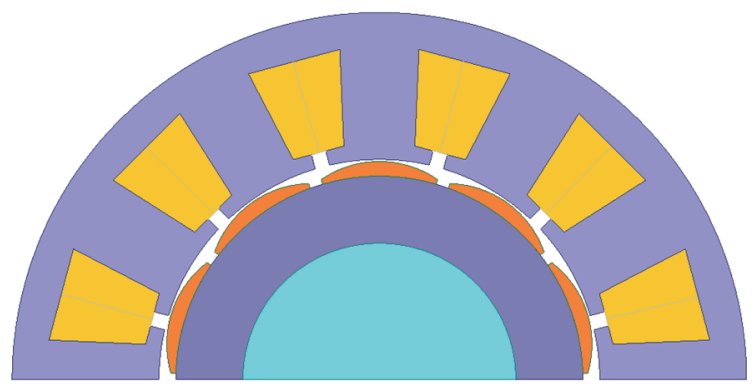

(c)

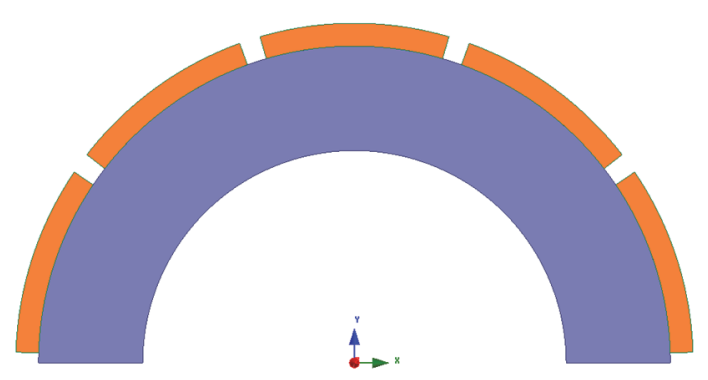

(b)

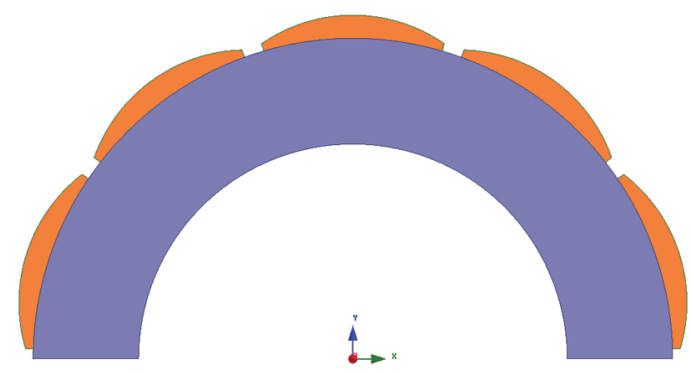

(d)

Figure 4. The cross-sections of the studied motor. (a) with the uniform rotor; (b) uniform rotor, (c) with the optimal rotor, $(\mathbf{d})$ optimal rotor.

Table 1. The specification of the investigated motors.

\begin{tabular}{cc}
\hline Parameter & Value \\
\hline Rotor Outer Diameter & $208 \mathrm{~mm}$ \\
\hline Rotor Inner Diameter & $130 \mathrm{~mm}$ \\
\hline Number of poles & 10 \\
\hline Pole Arc & $35^{\circ}$ \\
\hline Pole Thickness & $20 \mathrm{~mm}$ \\
\hline Magnet material & NEO-39SH \\
\hline Stator Outer Diameter & $350 \mathrm{~mm}$ \\
\hline Stator Inner Diameter & $210 \mathrm{~mm}$ \\
\hline Number of Slots & 12 \\
\hline Stator Tooth Width & $30 \mathrm{~mm}$ \\
\hline Stator Yoke Width & $26 \mathrm{~mm}$ \\
\hline Slot Open & $7 \mathrm{~mm}$ \\
\hline Tip Thickness & $2.5 \mathrm{~mm}$ \\
\hline Slot Skew & $0^{\circ}$ \\
\hline Stator Length & $100 \mathrm{~mm}$ \\
\hline Lamination material & $\mathrm{M} 19-0.5 \mathrm{~mm}$ \\
\hline
\end{tabular}

The 2D finite element method is applied to the performance calculation of the motor with uniform and non-uniform rotor shapes. The magnetic field distribution in the studied motors is represented in Figure 5. Open circuit analytical and numerical comparisons of the cogging torque for both motors with initial and optimal magnet shapes are shown in Figure 6. The on-load comparison of the back electromotive force of the investigate motors with the initial and optimal magnet shapes is carried out analytically and numerically as shown in Figure 7. An analytical and numerical comparison of 
the radial flux density for the 12S-10P motor in an open circuit and on-load condition is shown in Figure 8. An analytical and numerical comparison of tangential flux density for the 12S-10P motor in open circuit and on-load condition is shown in Figure 9. An on-load comparison of the electromagnetic torque of the 12S-10P motor with the initial and optimal magnet shapes is shown in Figure 10.

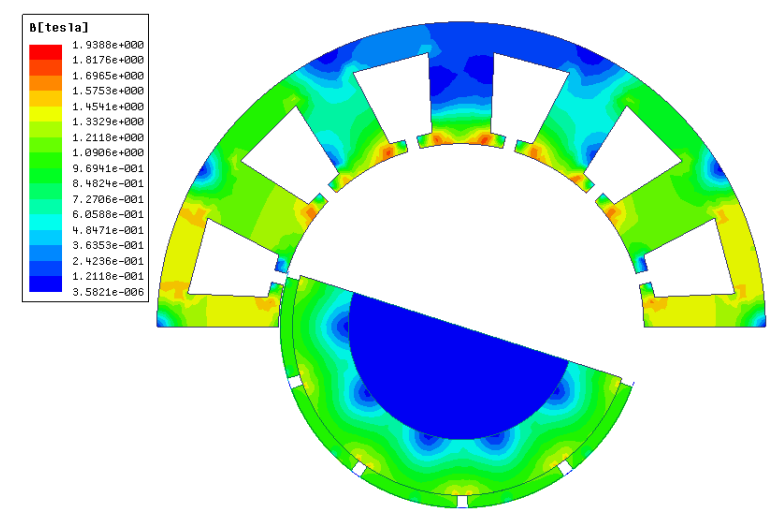

(a)

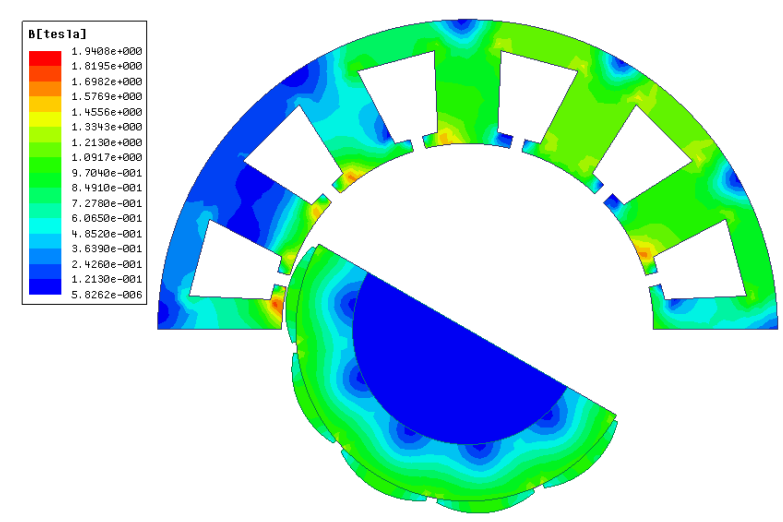

(b)

Figure 5. The magnetic field distribution in the 12S-10P motor. (a) Initial magnet shape; (b) Optimal magnet shape.

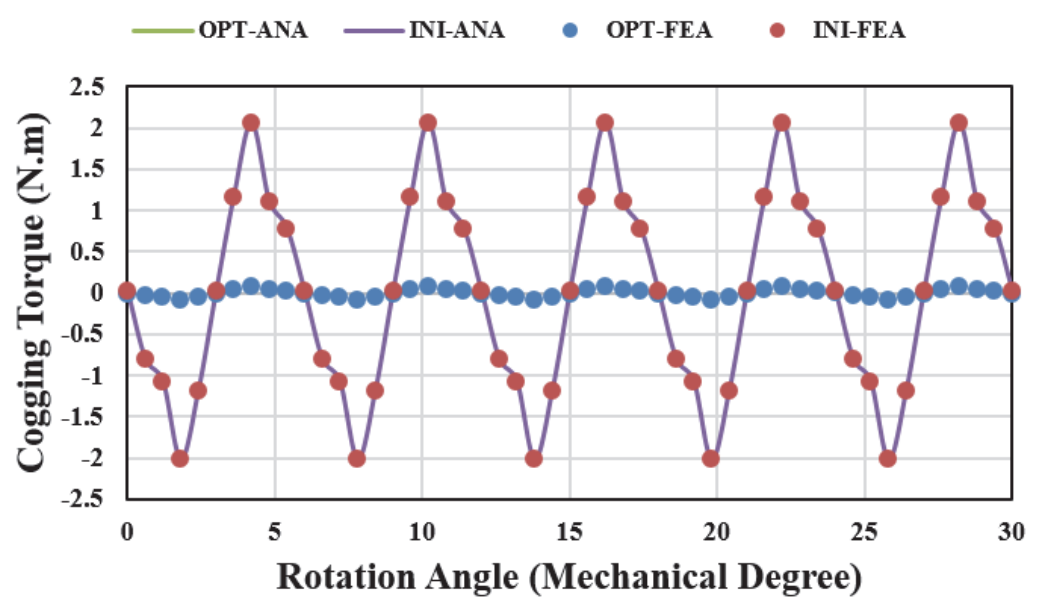

Figure 6. An open circuit analytical and numerical comparison of the cogging torque. 


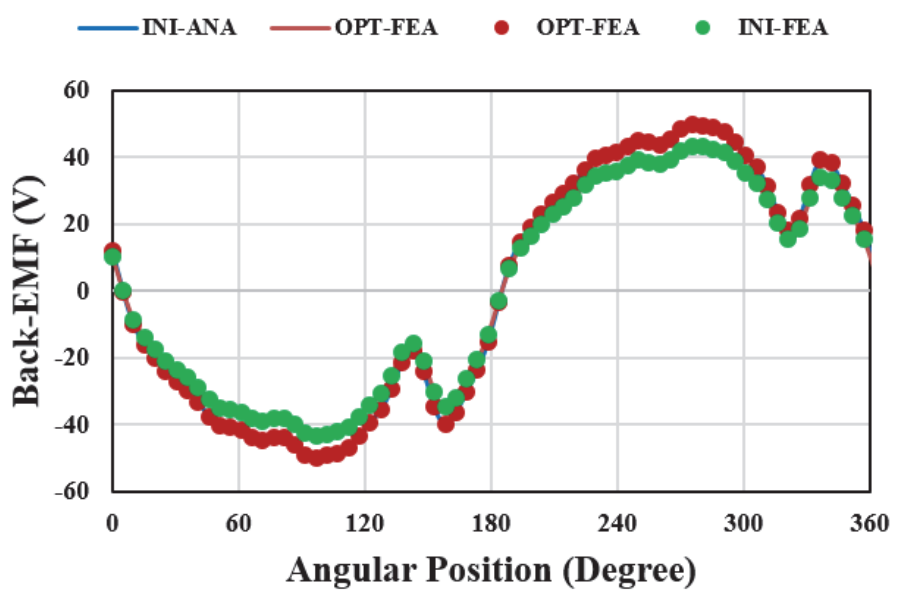

Figure 7. An on-load analytical and numerical comparison of Back-EMF.

- FEA -ANA

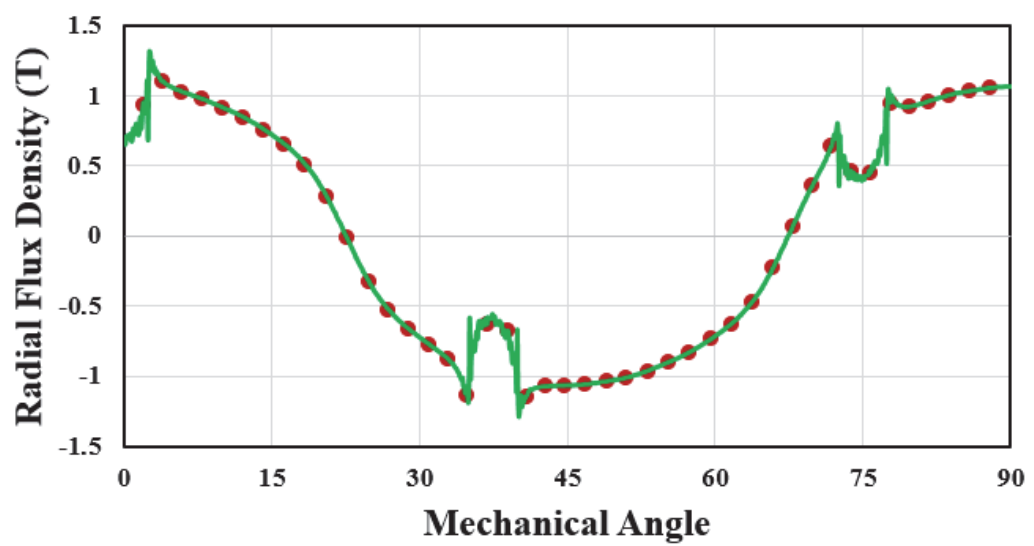

(a)

- FEA - ANA

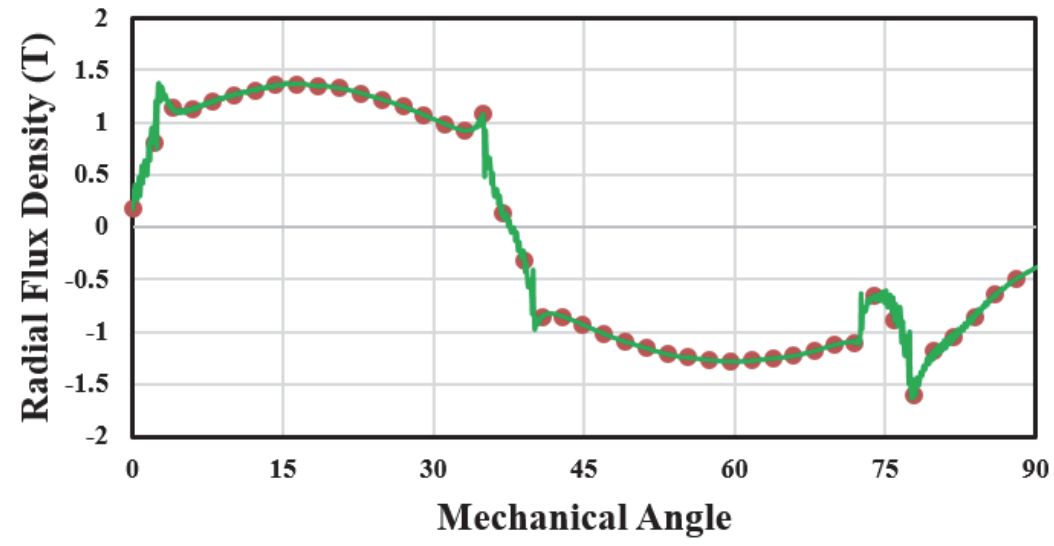

(b)

Figure 8. An analytical and numerical comparison of radial flux density for the 12S-10P motor. (a) Open circuit condition; (b) On-load condition. 


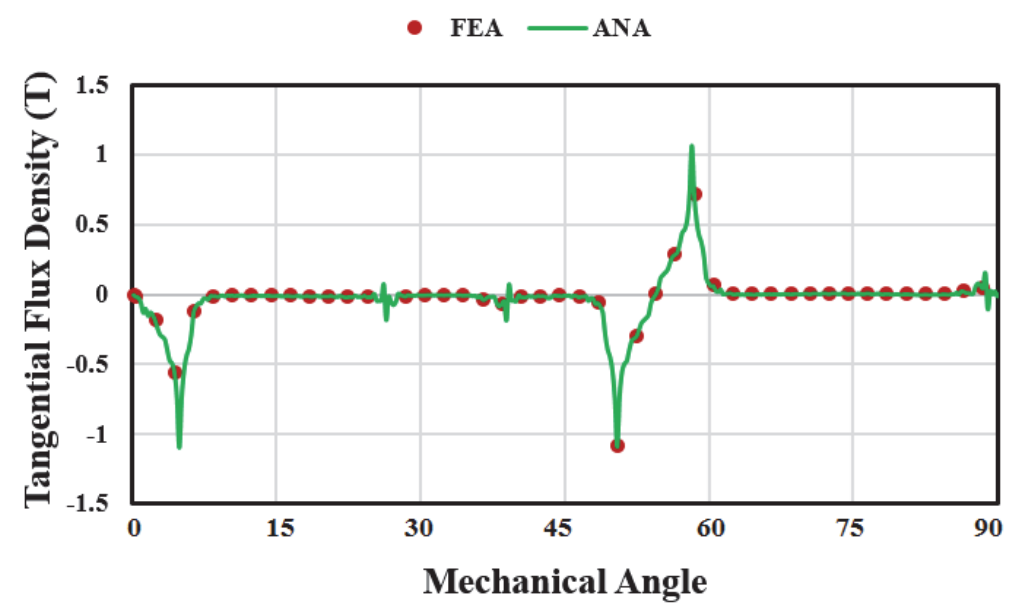

(a)

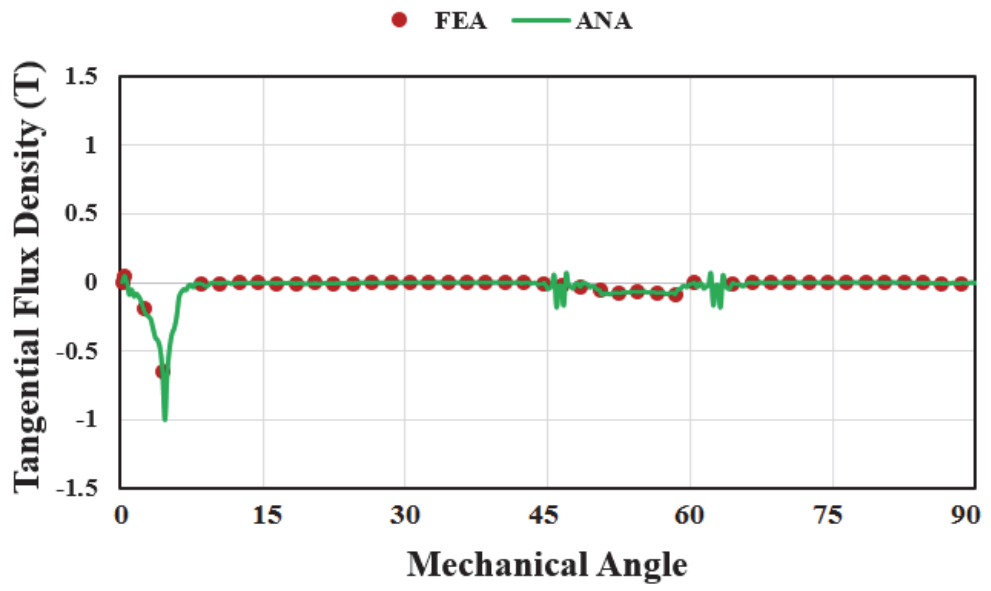

(b)

Figure 9. An analytical and numerical comparison of the tangential flux density for the 12S-10P motor. (a) Open circuit condition; (b) On-load condition.

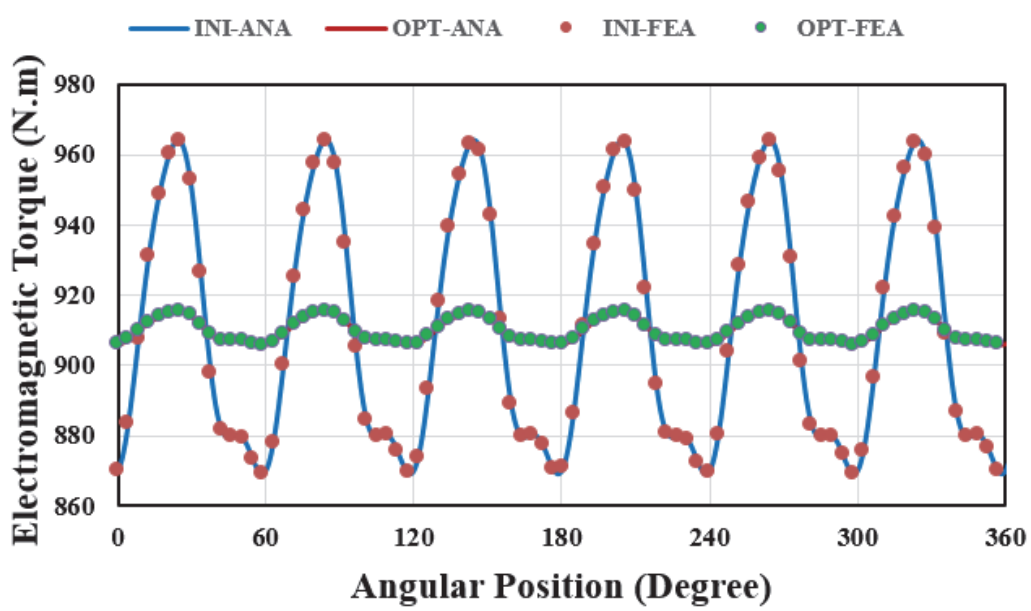

Figure 10. An on-load analytical and numerical comparison of the electromagnetic torque for the 12S-10P motor. 


\section{Conclusions}

A mathematical expression for the optimal magnet shape in surface mounted permanent magnet machines was considered in this paper. The Fourier analysis method based on the subdomain method using hyperbolic functions is applied to derive the analytical expressions for the calculation of magnetic vector potential, magnetic flux density, cogging torque, electromagnetic torque and back-electromotive force in surface-mounted permanent magnet machines. This model is applied for the performance computation of a 12S-10P surface-mounted permanent magnet motor. The results of the proposed model have been verified thanks to the FEA results. In future work, the iron permeability for global saturation can be considered in the analytical model by Dubas' superposition technique $[35,36]$.

Conflicts of Interest: The author declares no conflict of interest.

\section{References}

1. Jahns, T.M.; Soong, W.L. Pulsating torque minimization techniques for permanent magnet AC motor drives-A review. IEEE Trans. Ind. Electron. 1996, 43, 321-330. [CrossRef]

2. Bianchi, N.; Bolognani, S. Design techniques for reducing the cogging torque in surface-mounted PM motors. IEEE Trans. Ind. Appl. 2002, 38, 1259-1265. [CrossRef]

3. Lukaniszyn, M.; Jagiela, M.; Wrobel, R. Optimization of permanent magnet shape for minimum cogging torque using a genetic algorithm. IEEE Trans. Magn. 2004, 40, 1228-1231. [CrossRef]

4. Lateb, R.; Takorabet, N.; Meibody-Tabar, F. Effect of magnet segmentation on the cogging torque in surface-mounted permanent-magnet motors. IEEE Trans. Magn. 2006, 42, 442-445. [CrossRef]

5. Ackermann, B.; Sottek, R.; Janssen, J.H.H.; van Steen, R.I. New technique for reducing cogging torque in a class of brushless DC motors. IEE Proc. B Electric Power Appl. 1992, 139, 315-320. [CrossRef]

6. Ishikawa, T.; Slemon, G.R. A method of reducing ripple torque in permanent magnet motors without skewing. IEEE Trans. Magn. 1993, 29, 2028-2031. [CrossRef]

7. Keyhani, C.B.; Studer, T.; Sebastian, S.K.; Murthy, A. Study of cogging torque in permanent magnet machines. Electric Mach. Power Syst. 1999, 27, 665-678. [CrossRef]

8. Li, T.; Slemon, G. Reduction of cogging torque in permanent magnet motors. IEEE Trans. Magn. 1988, 24, 2901-2903.

9. Hwang, C.C.; John, S.B.; Wu, S.S. Reduction of cogging torque in spindle motors for CD-ROM drive. IEEE Trans. Magn. 1998, 34, 468-470. [CrossRef]

10. Jabbari, A.; Shakeri, M.; Nabavi Niaki, S.A. Pole shape optimization of permanent magnet synchronous motors using the reduced basis technique. Iran. J. Electron. Electr. Eng. 2010, 6, 48-55.

11. Markovic, M.; Jufer, M.; Perriard, Y. Reducing the cogging torque in brushless DC motors by using conformal mappings. IEEE Trans. Magn. 2004, 40, 451-455. [CrossRef]

12. Zarko, D.; Ban, D.; Lipo, T.A. Analytical calculation of magnetic field distribution in the slotted air gap of a surface permanent-magnet motor using complex relative air-gap permeance. IEEE Trans. Magn. 2006, 42, 1828-1837. [CrossRef]

13. Boughrara, K.; Zarko, D.; Ibtiouen, R.; Touhami, O.; Rezzoug, A. Magnetic field analysis of inset and surface-mounted permanent-magnet synchronous motors using Schwarz-Christoffel transformation. IEEE Trans. Magn. 2009, 45, 3166-3178. [CrossRef]

14. Ilhan, E.; Gysen, B.L.J.; Paulides, J.J.H.; Lomonova, E.A. Analytical hybrid model for flux switching permanent magnet machines. IEEE Trans. Magn. 2010, 46, 1762-1765. [CrossRef]

15. Tang, Y.; Motoasca, T.E.; Paulides, J.J.H.; Lomonova, E.A. Analytical modeling of flux-switching machines using variable global reluctance networks. In Proceedings of the 2012 XXth International Conference on Electrical Machines, Marseille, France, 2-5 September 2012; pp. 2792-2798.

16. Hua, W.; Zhang, G.; Cheng, M.; Dong, J. Electromagnetic performance analysis of hybrid-excited flux-switching machines by a nonlinear magnetic network model. IEEE Trans. Magn. 2011, 47, 3216-3219. [CrossRef]

17. Gu, Q.; Gao, H. Effect of slotting in PM electric machines. Electric Mach. Power Syst. 1985, 10, 273-284. 
18. Boules, N. Prediction of no-load flux density distribution in permanent magnet machines. IEEE Trans. Ind. Appl. 1985, 3, 633-643. [CrossRef]

19. Ackermann, B.; Sottek, R. Analytical modeling of the cogging torque in permanent magnet motors. Electr. Eng. Archiv fur Elektrotechnik 1995, 78, 117-125. [CrossRef]

20. Radun, A. Analytical calculation of the switched reluctance motor's unaligned inductance. IEEE Trans. Magn. 1999, 35, 4473-4481. [CrossRef]

21. Rasmussen, K.F.; Davies, J.H.; Miller, T.J.E.; McGelp, M.I.; Olaru, M. Analytical and numerical computation of air-gap magnetic fields in brushless motors with surface permanent magnets. IEEE Trans. Ind. Appl. 2000, $36,1547-1554$.

22. Wang, X.; Li, Q.; Wang, S.; Li, Q. Analytical calculation of air-gap magnetic field distribution and instantaneous characteristics of brushless DC motors. IEEE Trans. Energy Convers. 2003, 18, 424-432. [CrossRef]

23. Liu, Z.J.; Li, J.T. Analytical solution of air-gap field in permanent-magnet motors taking into account the effect of pole transition over slots. IEEE Trans. Magn. 2007, 43, 3872-3883. [CrossRef]

24. Liu, Z.J.; Li, J.T.; Jiang, Q. An improved analytical solution for predicting magnetic forces in permanent magnet motors. J. Appl. Phys. 2008, 103, 07F135. [CrossRef]

25. Liu, Z.J.; Li, J.T. Accurate prediction of magnetic field and magnetic forces in permanent magnet motors using an analytical solution. IEEE Trans. Energy Convers. 2008, 23, 717-726. [CrossRef]

26. Kumar, P.; Bauer, P. Improved analytical model of a permanent-magnet brushless DC motor. IEEE Trans. Magn. 2008, 44, 2299-2309. [CrossRef]

27. Lubin, T.; Mezani, S.; Rezzoug, A. Exact analytical method for magnetic field computation in the air gap of cylindrical electrical machines considering slotting effects. IEEE Trans. Magn. 2010, 46, 1092-1099. [CrossRef]

28. Gysen, B.L.; Ilhan, E.; Meessen, K.J.; Paulides, J.J.; Lomonova, E.A. Modeling of flux switching permanent magnet machines with fourier analysis. IEEE Trans. Magn. 2010, 46, 1499-1502. [CrossRef]

29. Boughrara, K.; Ibtiouen, R.; Lubin, T. Analytical prediction of magnetic field in parallel double excitation and spoke-type permanent-magnet machines accounting for tooth-tips and shape of polar pieces. IEEE Trans. Magn. 2012, 48, 2121-2137. [CrossRef]

30. Boughrara, K.; Lubin, T.; Ibtiouen, R. General subdomain model for predicting magnetic field in internal and external rotor multiphase flux-switching machines topologies. IEEE Trans. Magn. 2013, 49, 5310-5325. [CrossRef]

31. Tiang, T.L.; Ishak, D.; Jamil, M.K.M. Complete subdomain model for surface-mounted permanent magnet machines. In Proceedings of the 2014 IEEE Conference on Energy Conversion, Johor Bahru, Malaysia, 11-13 October 2014; pp. 140-145.

32. Liu, X.; Hu, H.; Zhao, J.; Belahcen, A.; Tang, L.; Yang, L. Analytical solution of the magnetic field and EMF calculation in ironless BLDC motor. IEEE Trans. Magn. 2016, 52, 1-10. [CrossRef]

33. Dubas, F.; Espanet, C. Analytical solution of the magnetic field in permanent-magnet motors taking into account slotting effect: No-load vector potential and flux density calculation. IEEE Trans. Magn. 2009, 45, 2097. [CrossRef]

34. Roubache, L.; Boughrara, K.; Dubas, F.; Ibtiouen, R. New subdomain technique for electromagnetic performances calculation in radial-flux electrical machines considering finite soft-magnetic material permeability. IEEE Trans. Magn. 2018. [CrossRef]

35. Dubas, F.; Boughrara, K. New scientific contribution on the 2-D subdomain technique in Cartesian coordinates: Taking into account of iron parts. Math. Comput. Appl. 2017, 22, 17.

36. Dubas, F.; Boughrara, K. New scientific contribution on the 2-D subdomain technique in polar coordinates: Taking into account of iron parts. Math. Comput. Appl. 2017, 22, 42.

37. Hannon, B.; Sergeant, P.; Dupré, L. Two-dimensional Fourier-based modeling of electric machines. In Proceedings of the 2017 IEEE International Electric Machines and Drives Conference, Miami, FL, USA, 21-24 May 2017; pp. 1-8.

38. Jabbari, A. 2D Analytical Modeling of Magnetic Vector Potential in Surface Mounted and Surface Inset Permanent Magnet Machines. Iran. J. Electr. Electron. Eng. 2017, 13, 362-373.

39. Jabbari, A. Exact analytical modeling of magnetic vector potential in surface inset permanent magnet DC machines considering magnet segmentation. J. Electr. Eng. 2018, 69, 39-45. [CrossRef] 
40. Jabbari, A. Analytical Modeling of Magnetic Field Distribution in Inner Rotor Brushless Magnet Segmented Surface Inset Permanent Magnet Machines. Iran. J. Electr. Electron. Eng. 2018, 14, 259-269.

41. Jabbari, A. Analytical Modeling of Magnetic Field Distribution in Multiphase H-Type Stator Core Permanent Magnet Flux Switching Machines. Iran. J. Sci. Tech. Trans. Electr. Eng. 2018, 3, 1-13. [CrossRef]

(c) 2018 by the author. Licensee MDPI, Basel, Switzerland. This article is an open access article distributed under the terms and conditions of the Creative Commons Attribution (CC BY) license (http:/ / creativecommons.org/licenses/by/4.0/). 